\title{
Early diagenesis of silica in Barents Sea sediments: a holistic laboratory and reaction-transport model assessment
}

\author{
JAMES WARD ${ }^{1}$, KATHARINE R. HENDRY ${ }^{1}$, SANDRA \\ ARNDT $^{2}$, REBECCA A PICKERING ${ }^{3}$, CHRISTIAN MÄRZ ${ }^{4}$, \\ JOHAN C. FAUST ${ }^{5}$, SIAN HENLEY ${ }^{6}$, JEFFREY KRAUSE ${ }^{7}$ \\ AND HONG CHIN NG ${ }^{1}$ \\ ${ }^{1}$ School of Earth Sciences, University of Bristol \\ ${ }^{2}$ Université Libre de Bruxelles \\ ${ }^{3}$ Lund University \\ ${ }^{4}$ School of Earth and Environment, University of Leeds \\ ${ }^{5}$ University of Leeds \\ ${ }^{6}$ University of Edinburgh \\ ${ }^{7}$ University of South Alabama \\ Presenting Author: jamespj.ward@bristol.ac.uk
}

The production of biogenic silica (BSi) by silicifying plankton, such as diatoms and radiolaria, intrinsically couples dissolved silica (DSi) to the biological pump, which coregulates atmospheric $\mathrm{CO}_{2}$. Environmental changes underway in the Arctic, such as rapid rates of warming and Atlantification threaten to notably perturb the silica cycle. Pelagic processes pertaining to this are receiving increasingly more attention, with recent studies demonstrating that DSi concentrations are decreasing over time in Atlantic waters flowing into the Arctic through the Barents Sea and that spring diatom blooms are now showing signs of DSi limitation, e.g. in the Svalbard region. However, compared to the pelagic processes little is known of how these changes may influence biogeochemical processes occurring at the seafloor. Stable silicon isotopes are a useful tool to investigate the mechanisms underlying the cycling of Si within shallow seafloor sediments, so as to determine their sensitivity to future changes in pelagic-benthic coupling. Here we present a comprehensive dataset of silicon isotopic compositions $\left(\delta^{30} \mathrm{Si}\right)$ in pore water DSi samples and operational reactive silica pools of the solid sediment phase, extracted using sequential digestions. These digestions revealed an isotopically light Si pool associated with early diagenetic products (e.g. metal oxides), a regionally variable BSi signal, and a ubiquitous phase likely dominated by lithogenic silica (LSi). Reaction-transport modelling shows that potentially up to $90 \%$ of the observed sedimentary DSi pool in the upper $30 \mathrm{~cm}$ is sourced from LSi and also indicates a strong influence on both the DSi concentration and isotopic composition of DSi from Fe (oxyhydr)oxides. This is consistent with very low surface sediment BSi contents $(\sim 0.4 \mathrm{wt} \%)$ and core top DSi concentrations $(\sim 4-14 \mu \mathrm{M})$ well below that of many detrital mineral solubilities $(\sim 30-300 \mu \mathrm{M})$. In summary, this study suggests that there may be an abiotic-mineral control on the magnitude and composition of benthic recycling fluxes of DSi. This has significant implications for the sensitivity of the Barents Sea benthic silica cycle to future stressors, as this could induce a certain degree of resilience to processes that strongly influence the pelagic realm. 